\title{
Comparative study of anthropometric and body composition variables, and functionality between elderly that perform regular or irregular physical activity
}

\author{
Estudo comparativo de variáveis antropométricas, de composição corporal e \\ de funcionalidade entre idosos que praticam atividade física regular e irregular
}

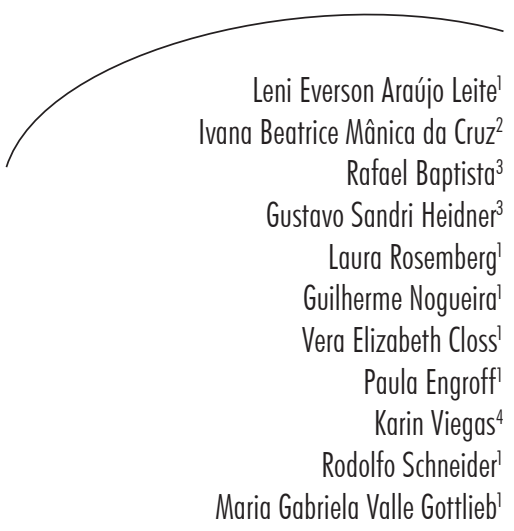

Abstract

Background: The impact of regular and irregular physical activity in body composition, muscle mass and strength of the elderly is not well studied yet. Objective: To compare anthropometric variables, muscle and fat thickness, mobility, handgrip and lower limb strength between regularly and irregularly active elderly classified by the International Physical Questionnaire Activity Questionnaire. Methods: A crosssectional study conducted with 75 elderly people (14 males and 61 females) who practiced regular $(\mathrm{RPA}=10)$ or irregular physical activity $(\mathrm{IPA}=65)$. Anthropometric variables (body mass index, circumferences and skinfolds), muscular and fat thickness (triceps, vastus lateralis and medial gastrocnemius [ultrasound]), handgrip strength (Crown dynamometer), lower limb strength (sit and stand up test) and mobility were collected from the sample. Physical activity was assessed by the International Physical Questionnaire Activity Questionnaire. Results: No significant differences were found in the anthropometric, skeletal muscle and fat mass and force variables between two groups $(\mathrm{p}>0.05)$. However, elders who practiced irregular physical activity presented best performance in the time up and go test than those who practiced regular physical activity $(\mathrm{p}=0.008)$. Results were independent of sex and age of subjects $(\mathrm{p}=0.017)$. Conclusion: The study showed no significant differences between elderly that performed physical activity in regular or irregular way in relation body composition and force parameters. However, the results suggest that even irregular physical activity can help the elderly individuals in the mobility, and prevent falls.

\footnotetext{
Programa de Pós-Graduação em Gerontologia Biomédica. Instituto de Geriatria e Gerontologia da Pontifícia Universidade Católica do Rio Grande do Sul.

2 Programa de Pós Graduação em Bioquímica Toxicológica e Programa de Pós Graduação em Farmacologia. Departamento de Ciências da Saúde da Universidade Federal de Santa Maria.

3 Faculdade de Educação Física e Ciências do Desporto da Pontifícia Universidade Católica do Rio Grande do Sul.

4 Departamento de Enfermagem da Universidade Federal de Ciências da Saúde de Porto Alegre.
}

Financial support: National Program of Post-doctoral of the CAPES (grants and fellowships- process n²785/09-9).

Correspondência / Correspondence

Maria Gabriela Valle Gottlieb

E-mail: maria.gottlieb@pucrs.br

Key words: Aging. Elderly. Body Composition. Physical Activity. Muscle Mass.

Functional Fitness. 


\section{Resumo}

Introdução: o impacto da atividade física regular e/ou irregular na composição corporal, massa e força muscular e funcionalidade em idosos é ainda pouco estudado. Objetivo: comparar variáveis antropométricas, espessura muscular e de gordura, mobilidade e força de preensão palmar de membros inferiores entre idosos regular e irregularmente ativos classificados pelo International Phisical Activity Questionnnaire. Método: estudo transversal com 75 idosos (14 homens e 61 mulheres) que praticavam atividade física regular $(\mathrm{AFR}=10)$ ou irregular (AFI=65). Variáveis antropométricas (índice de massa corporal, circunferências e dobras cutâneas), espessura muscular e de gordura (tríceps braquial, vasto lateral e gastrocnêmico medial [ultrassom]), força de preensão palmar (dinamômetro Crown), força de membros inferiores (teste de senta e levanta) e mobilidade foram coletadas da amostra de idosos. A atividade física foi avaliada através do International Phisical Activity Questionnnaire. Resultados: não foram encontradas diferenças significativas nas variáveis antropométricas, espessura muscular e de gordura e força entre os dois grupos ( $\mathrm{p}>0,05)$. No entanto, no grupo de idosos que praticavam atividade física irregular, foi obtido melhor desempenho no teste de mobilidade do que nos idosos que praticavam atividade física regular $(\mathrm{p}<0,008)$. Esse resultado foi independente de sexo e idade $(\mathrm{p}=0,017)$. Conclusão: o estudo não encontrou diferenças significativas entre os idosos que praticam atividade física de forma regular ou irregular em relação à composição corporal e parâmetros de força. Contudo, os resultados sugerem que a prática de atividade física irregular pode ajudar a mobilidade dos idosos e prevenir quedas.
Palavras-chave:

Envelhecimento. Idosos. Composição Corporal.

Atividade Motora. Massa muscular. Aptidão functional.

\section{BACKGROUND}

Aging changes in body composition, particularly the loss of skeletal muscle mass and strength, are related to reduced levels of daily activity and physical function that increase falls and unstable balance risk in elderly people. ${ }^{1}$ This condition can lead to sarcopenia, defined as a syndrome rather than as pathology, where the subject is affected by a decrease of muscle mass and function associated with age. Several studies show that regular physical activity can improve the health of older people and contribute to the primary and secondary prevention of many chronic diseases, including sarcopenia. ${ }^{2}$

Futhermore, a sedentary lifestyle is associated with many chronic diseases, the change in body composition (increased fat and decreased muscle mass) and development of premature death. ${ }^{3}$ However, no studies in the literature compare regular and irregular physical activity and its effects on muscle and fat mass, body composition and physical function in elderly. Research evaluating these parameters in individuals who are physically active or sedentary practices suggests that regular physical activity can improve muscle mass and grip strength and lower limb mobility. ${ }^{4}$

The physical activity preventive programs are now very popular since exercise plays a critical role in promoting healthy aging and in the management of chronic illnesses. ${ }^{4}$ We can recognize two general categories of physical activity performed by elderly people: regular physical activity, defined as the participation in an exercise program (2-3 times a week, accompanied by a trained professional); irregular physical activity, without regular professional advisement, performed by elders at home. There is clear evidence that a targeted supervised home exercise program of strength and balance exercise and walking practice, prescribed by a trained health professional, can prevent falls among older community dwellers. ${ }^{5}$ However, the impact of regular and irregular physical activity in body composition, muscle mass and strength and functional fitness on elderly people living in the community is yet not well studied. 
Therefore, this study compared anthropometric, muscle and fat thickness variables, mobility, handgrip and lower limb strength between elderly who practice regular and irregular actives classified by the International Physical Questionnaire Activity Questionnaire (IPAQ).

\section{METHODS}

Study design

This was a cross-sectional study comparing elderly subjects living in community grouped in regular physical activity (RPA) to irregular physical activity subjects (IPA), determined by the International Physical Activity Questionnaire (IPAQ, 8 version, long form), an instrument previously validated to Brazilian elderly subjects by Matsudo et al. ${ }^{6}$ The RPA group comprised active and very active elderly. These are the individuals who performed the following activities (Guidelines for Data Processing and Analysis of the International Physical Activity Questionnaire):?

1) Very active: (a) vigorous activity: $\geq 5$ days / week and $\geq 30$ minutes per session and/or (b) vigorous: $\geq 3$ days/week and $\geq 20$ minutes per session + moderate and/or brisk walk: $\geq 5$ days / week and $\geq 30$ minutes per session.

2) Active: (a) vigorous activity: $\geq 3$ days / week and $\geq 20$ minutes per session, and/or (b) moderate or brisk walk: $\geq 5$ days / week and $\geq 30$ minutes per session, and/or (c) any activity added: $\geq 5$ days / week and $\geq 150$ minutes / week (walking + moderate + vigorous).

The IPA group was composed by individuals who performed physical activity, but insufficient to be classified as regular, as they did not meet the recommendations regarding frequency and/ or duration. To accomplish this classification we summed up the frequency and duration of different types of activities (walking + moderate activity + vigorous activity). This group is also classified according to whether or not they comply with some of the recommended criteria of frequency: 5 days per week or total duration of 150 minutes per week. The questionnaire assessed the physical activity performed at work, mobility, household activities and free time.

This study was conducted in the Outpatient Clinic of the Geriatric Service of Hospital São Lucas of Pontifical Catholic University of Rio Grande do Sul (PUCRS), with 75 patients (IPA=65, RPA=10), 14 males and 61 females that practiced physical activity on a regular or irregular manner from March to September 2010. The differences between sample number of IPA and RPA reflect the lower prevalence of physically active elderly who perform regular exercises and did not present any exclusion criteria to participate of the study. Therefore, the samples included in the two elderly groups compared here were considered realistic. The criteria used for inclusion of patients were: age of 60 years or older and who practiced physical activity on a regular or irregular manner. Sedentary individuals, with advanced arthrosis and osteoporosis, recent fractures, cognitive impairment or dementia were excluded from the study.

The RPA and IPA samples were adjusted to sex, age and previous general morbidities presenting similar conditions of vision, hearing and autonomy.

\section{Variables analyzed}

Anthropometry: weight was measured on a calibrated Welmy digital scale, and standing height was measured with a stadiometer. Participants were assessed dressed in hospital gown and barefoot, positioned in the center of the platform of the scale, with arms extended and standing straight. BMI was calculated through Quetelet Index. ${ }^{8}$ The assessment followed the cutoff points for the classification of the nutritional status of elderly individuals, recommended by Lipschitz. ${ }^{9}$ Waist circumference (WC) was measured with a nonelastic metric tape, at the midpoint between the last rib and iliac crest, with the individual standing and breathing normally, taking care not to squeeze the skin. The values obtained were compared with the cutoff points proposed by 
International Diabetes Federation (IDF). ${ }^{10}$ Arm circumference was measured in centimeters, in the right arm. For the location of the midpoint between the acromion and olecranon, the elderly should be standing with weight equally distributed on both feet, with the arm to be evaluated with the elbow bent at a $90^{\circ}$, and with the palm of the hand in supine position. Then, with his arm extended in the anatomical state of relaxation throughout the body with the palm facing the thigh, the set point was measured by a flexible tape, on an adjusted basis, avoiding compression of the skin, and the reading on to the nearest millimeter. ${ }^{11}$

The thigh circumference was measured with the subject standing with the heels shoulder width apart and the weight evenly distributed on both feet. The measuring tape was placed horizontally around the thigh, midway between the midpoint of the inguinal crease and the proximal border of the patella. The calf circumference was measured with the subject sitting with the legs loose, without touching the floor, and the tape positioned horizontally in the area of the biggest diameter of the calf. Skin fold thicknesses were evaluated with Cescorf® (Cescorf, Brazil) scientific skinfold caliper, using the method described by Lohman et al.$^{12}$

The tricipital skin fold thickness was measured in the midline of the posterior aspect of the right arm, at a point midway between the lateral projection of the acromion process of the scapula and the inferior margin of the olecranon process of the ulna. The elderly should be standing with weight equally distributed on both feet, shoulders and arms relaxed along the trunk side. Bicipital skin fold thickness was measured on the anterior aspect of the arm, one centimeter above the line marked for measurement of the arm circumference, with the subject standing with arms relaxed at both sides of the body, and the palm directed anteriorly. Thigh skin fold thickness was measured in the midline of the anterior aspect of the thigh, midway between the inguinal crease and the proximal border of the patella. Body weight was shifted to the other foot while the leg on the side of the measurement was relaxed with the knee slightly flexed. For the measurement of the medial calf skin fold, the subject was sitting with the knee flexed at about $90^{\circ}$. The fold was measured at the largest circumference of the leg.

Assessment of muscle thickness in vivo was performed by means of ultrasound, using an ultrasound (DP6600, Mindray Bio-Medical Electronics Co.) with a linear array probe of 7.5 MHz. Muscle thickness was calculated from three measurements of the distance between the superficial and deep aponeurosis in a specific location of each muscle examined from an image made with the probe in the sagittal plane, covered with echogenic gel without skin compressions. The muscles examined were the triceps brachial (long head), vastus lateralis and medial gastrocnemius. Measurement points were precisely located and marked.

The evaluation of the triceps was on the posterior surface of the arm, at $40 \%$ of the length of it from the distance between the acromion process and lateral epicondyle of the humerus with proximal positioning of the probe. The evaluation of the vastus lateralis, on the anterior surface of the thigh, was at $70 \%$ from the same measuring of the distance between the greater trochanter and the articular cleft between the tibial and femoral condyles, proximal positioning of the probe. And the evaluation of the medial gastrocnemius, on the posterior surface of the leg, was at $30 \%$ proximal from the distance between the articular cleft between the tibial and femoral condyles and the lateral malleolus of the tibia with proximal positioning the probe. ${ }^{13}$

\section{Functional fitness variables}

The measurements of handgrip strength were performed with a dynamometer (Crow mark) with a threshold of 50 kg.f (kilogram 
force), with divisions of $0.5 \mathrm{~kg} . f$ (grams force). The subject should sit down an office chair (without armrests) with a straight back, keeping the angle of knee flexion at $90^{\circ}$, shoulder positioned in adduction and neutral rotation, elbow flexed at $90^{\circ}$ with the forearm in half pronation and the wrist neutral, and allowed to move it up to $30^{\circ}$ of extension. The arm should be kept suspended in the air with hand placed on the dynamometer, which was held by the evaluator. Three measurements were performed with an interval of 60 seconds between them, alternating between the dominant and no dominant sides, recording the highest value. ${ }^{14}$

Lower limbs strength was measured by the sit-to-stand test. Strength and endurance of the lower limbs were verified by measuring in a time dependent way. The individual started the test in the sitting position, arms crossed over his chest, and got up five times as fast as possible, without any pause. The test is considered successful when performed in a time equal to or less than 30 seconds. Before the test, after a demonstration, the examiner asked the elder if he felt confident to get up quickly from a chair five times in a row. If so, he proceeded to demonstrate. After this procedure, the elder considered if he felt confident to stand up from a chair and sit down five times in a row, now with his arms folded across his chest. If so, the test was then performed. If the subject showed fatigue, he was given a short break (1-3 minutes). ${ }^{15-17}$

Physical function (mobility) was determined by the Timed up and go test (TUG), which measures the time in seconds taken to stand from a seated position, walk three meters, turn around, walk back, and sit down again. ${ }^{18}$

\section{Statistical analysis}

The results are reported as means \pm standard deviation or percentages. All the analyses were carried out using the Statistical Package for Social Studies SPSS version 18.0 (Inc., Chicago, IL). The differences between RPA and IPA groups were evaluated by the Student's $t$ test for quantitative variables and by the chi-square test for categorical variables. The multivariate logistic regression analysis (Backward Wald method) was performed to evaluate the potential influence of sex, age, and health variables in the results obtained. The alpha value considered was $\mathrm{p}=0.05$. All $\mathrm{p}$ values were two-tailed. A $\mathrm{p}$ value of $<0.05$ was considered to be statistically significant.

\section{Ethical aspects}

The research was approved by the Research Ethics Committee of PUCRS (protocol 10/05159), and the term of free and informed consent was obtained from all participants.

\section{RESULTS}

The average age in the RPA group was $73.4 \pm 8.4$ years, and in the IPA group was $73.3 \pm 6.7$ years $(p=0.974)$. Age, anthropometric variables and skeletal muscle and fat thickness were compared between the two elderly groups and no significant differences were found. The most of the anthropometric and skeletal muscle and fat thickness measurements were similar between the two groups $(\mathrm{p}>0.05)$. The results are presented in table 1. 
Table 1. Comparison of age, anthropometric variables, fat and muscle mass thickness between regular very active (RPA) and irregular active (IPA) elderly subjects, Porto Alegre-RS, 2012.

\begin{tabular}{|c|c|c|c|}
\hline \multirow[t]{2}{*}{ Variables } & \multicolumn{2}{|c|}{ Elderly physical activity pattern } & \multirow[t]{2}{*}{$\mathrm{p}$} \\
\hline & $\begin{array}{c}\text { RPA } \\
\text { Mean } \pm \text { SD }\end{array}$ & $\begin{array}{c}\text { IPA } \\
\text { Mean } \pm \text { SD }\end{array}$ & \\
\hline Age (years) & $73.4 \pm 8.4$ & $73.3 \pm 6.7$ & 0.974 \\
\hline Height (m) & $1.60 \pm 0.51$ & $1.77 \pm 0.42$ & 0.345 \\
\hline Body Mass Index $\left(\mathrm{kg} / \mathrm{m}^{2}\right)$ & $31.70 \pm 8.57$ & $29.12 \pm 5.64$ & 0.379 \\
\hline \multicolumn{4}{|l|}{ Circumferences } \\
\hline Waist (cm) & $94.00 \pm 12.98$ & $90.20 \pm 12.87$ & 0.406 \\
\hline $\operatorname{Arm}(\mathrm{cm})$ & $34.20 \pm 5.67$ & $32.09 \pm 4.54$ & 0.287 \\
\hline Thigh (cm) & $51.60 \pm 10.08$ & $50.95 \pm 5.77$ & 0.847 \\
\hline Calf (cm) & $37.40 \pm 6.45$ & $37.51 \pm 3.86$ & 0.960 \\
\hline \multicolumn{4}{|l|}{ Skin fold thickness } \\
\hline Thigh (mm) & $24.40 \pm 9.26$ & $21.35 \pm 5.84$ & 0.336 \\
\hline Calf $(\mathrm{mm})$ & $20.70 \pm 9.33$ & $18.52 \pm 6.67$ & \\
\hline Triceps (mm) & $21.50 \pm 8.31$ & $17.69 \pm 5.01$ & 0.189 \\
\hline Biceps (mm) & $16.70 \pm 8.79$ & $14.22 \pm 4.73$ & 0.403 \\
\hline \multicolumn{4}{|l|}{ Muscle thickness } \\
\hline Brachial triceps (mm) & $13.34 \pm 1.61$ & $14.38 \pm 3.55$ & 0.418 \\
\hline Vastus lateralis (mm) & $16.11 \pm 4.69$ & $18.08 \pm 4.72$ & 0.296 \\
\hline Medial gastrocnemius (mm) & $12.93 \pm 4.24$ & $14.57 \pm 3.69$ & 0.326 \\
\hline \multicolumn{4}{|l|}{ Fat thickness } \\
\hline Brachial triceps (mm) & $14.71 \pm 5.67$ & $15.64 \pm 6.32$ & 0.696 \\
\hline Vastus lateralis (mm) & $18.14 \pm 16.45$ & $12.66 \pm 6.65$ & 0.382 \\
\hline Medial gastrocnemius (mm) & $11.60 \pm 7.06$ & $8.73 \pm 3.60$ & 0.294 \\
\hline
\end{tabular}

$\mathrm{SD}=$ standard deviation; statistical comparison performed by Student $t$ test.

No significant differences were found in relation to handgrip and lower limb strength between the groups investigated $(\mathrm{p}>0.05)$. IPA elders presented a better performance in the TUG test than the RPA elder ( $\mathrm{p}=0.008)$. Force and mobility were compared between groups and the results are presented in table 2 . These results were independent of the sex and age of subjects $(p=0.017)$. 
Table 2. Comparison of handgrip and leg strength and mobility between regular active (RPA) and irregular active (IPA) elderly subjects. Porto Alegre-RS, 2012

\begin{tabular}{lccc}
\hline \multicolumn{1}{c}{ Variables } & \multicolumn{2}{c}{ Elderly physical activity pattern } & \multirow{2}{*}{$\mathrm{p}$} \\
\cline { 2 - 3 } & $\begin{array}{c}\mathrm{RPA} \\
\mathrm{Mean} \pm \mathrm{SD}\end{array}$ & $\mathrm{IPA}$ & \\
& $21.30 \pm 5.94$ & $22.83 \pm 8.80$ & 0.492 \\
\hline Handgrip strength right $(\mathrm{kg} / \mathrm{f})$ & $20.70 \pm 5.33$ & $22.03 \pm 8.99$ & 0.651 \\
Handgrip strength left $(\mathrm{kg} / \mathrm{f})$ & $13.78 \pm 3.99$ & $11.92 \pm 4.14$ & 0.211 \\
Leg strength (sit and stand) $(\mathrm{sec})$ & $14.30 \pm 6.20$ & $10.55 \pm 3.62$ & 0.008 \\
Mobility (TUG test) $(\mathrm{sec})$ & & & \\
\hline
\end{tabular}

$\mathrm{SD}=$ standard deviation; statistical comparison performed by Student $t$ test. TUG $=$ Timed Up \& Go test.

\section{DISCUSSION}

The results showed no impact of regular physical activity on physical parameters as body mass index and other anthropometric and body composition variables. On the other hand, the only parameter that presents significant difference between groups was the TUG test, just in the elderly included in the IPA group, which showed the best results.

It is important to note that this is the first study to make this kind of comparison of the body composition and functionality of the elderly that practice regular or irregular physical activity.

Physical activity has been reported as a predictive value to the health condition of the elderly people, preventing chronic diseases and improving systemically the body functions. Many studies show that regular physical activity improves body composition, blood lipid profile, glucose homeostasis, serum insulin levels and several clinical conditions in the diverse populations and is age-related..$^{19-21}$

Due to the important health effects related to physical activity, we questioned if this variable, when practiced regularly or irregularly by elderly subjects, could present differences among parameters associated to the aging process (including body composition changes) and skeletal muscle modifications and functionality. Several studies show that regular physical activity can improve the health status of elderly individuals and contribute to both primary and secondary prevention of many chronic diseases and conditions, including sarcopenia. ${ }^{22-25}$ It is known that sedentary life is associated with many chronic diseases, modifications in the body composition (fat increase and muscle mass decrease) and premature death. ${ }^{25}$

However, there are no studies in the literature comparing the regular and irregular physical activity in the muscle and fat thickness, body composition and functional fitness in elderly population. Major investigations evaluate these parameters in subjects who are sedentary or physical active, and suggest that the regular practice of physical activity improves muscle mass and strength, and mobility. ${ }^{4}$

However, some studies indicate that the irregular practice of physical activity may be dangerous to health. For example, Wang et al. examined the effect of regular ongoing exercise lifestyle on the mental and physical health of a group of independent community-dwelling Taiwanese elderly over a 2 -year period. ${ }^{26}$ The 
results showed that the regular exercise group showed significantly less depression $(\mathrm{p}=0.03)$ and tended to regress less on the performance tests $(\mathrm{p}=0.025-0.410)$ across two years, compared to the irregular exercise group. In a cohort study performed by Wu et al. with 1,321 community-dwelling people aged 65 years or older (ten years of follow-up), the incidence of chronic activities of daily living (ADL) disability was estimated, and analyzed sociodemographic, health status, adverse lifestyle, and leisure-time physical activity predictors for chronic ADL disability. The results showed that the risk of chronic ADL disability was inversely related with routine exercise ( $R R=0.52$; 95\% CI, 0.390.68). In other words, the lack of routine exercise is also a significant predictor of ADL disability in older adults. ${ }^{27}$

The results, when RPA and IPA were compared, did not detect important differences in body composition, muscle and fat mass, handgrip and leg strength. The only significant difference was in mobility of the elders analyzed by the TUG test. This test is associated with a history of fall in elderly people. A systematic review about TUG test and risk of falls in elderly age was recently performed by Beauchet et al. ${ }^{28}$ The authors estimated that cut-off time separating non-fallers and fallers varied from 10 to 32.6 seconds.

In this study, 50 subjects presented a TUG $\leq$ 10 seconds and just three subjects performed the test with $\geq 20$ seconds. Therefore, despite the RPA subjects present TUG values significantly higher than found in IPA subjects, perhaps these differences do not mean an increase in the risk of falling in the RPA group.

A cross-sectional study performed with 1,059 Brazilian elderly women showed that inactive women had higher odds ratio for type 2 diabetes (T2D) when compared with active ones, within the same waist circumference (WC) group. Inactive women with $\mathrm{WC}>$ or $=94.0 \mathrm{~cm}$ had an odds ratio of $5.8(95 \% \mathrm{IC} 1.3-25.3)$. In this case, regular exercise practice could reduce body fatness and may be beneficial in reducing the prevalence of T2D in older ages. ${ }^{29}$

The results of present study partially corroborate these data and also show that physical activity, although performed in irregular way, does help elderly individuals to maintain anthropometric parameters near the recommended standards. Despite the sample being overweight (IPA group) and obesity (RPA group), which is a common finding in the elderly population, IPA group showed mean BMI, skin folds and circumferences smaller than the AFR group. Even though this difference was not statistically significant, clinically this result seems to be favorable to health.

Furthermore, it is important to note that thinness and malnutrition in the elderly are important predictive to chronic diseases. Investigation analyzing the influence of regular physical activity during leisure time (LTPA) and occupational physical activity (OPA) on circulating levels of several parameters associated with an increased risk of cardiovascular disease was conducted in 932 individuals by Sofi et al. ${ }^{30}$ These authors found a LTPA inversely related to BMI, hip circumference, diastolic blood pressure and triglycerides, as well as directly correlated with high-density lipoprotein (HDL) cholesterol. Likewise, a higher OPA was found to be associated with higher HDL cholesterol levels.

A moderate-to-high intensity of LTPA was able to confer significant protection against having abnormal levels of BMI, WC and triglycerides, main features of the metabolic syndrome, whereas no associations between these parameters and OPA were observed. These results suggest that even physical activity during leisure time may modulate the anthropometrical and some biochemical parameters. ${ }^{30}$ Since we did not find differences between anthropometric parameters in RPA and IPA subjects, we can speculate that despite the fact that physical activity is irregular, the intensity can be similar 
and act beneficially in the body system. However, complementary studies to test this suggestion need to be performed.

We also did not find differences related to the skeletal muscle and adipose tissue between RPA and IPA subjects. Increase in adipose tissue and decrease of skeletal muscle is a characteristic highly prevalent in elderly people being considered as a "biological aging adaptation". However, these characteristics may be modulated by physical activity showed in studies such as performed by Goodpaster et al. ${ }^{31}$ These authors examined the effects of physical activity on strength and skeletal muscle fat infiltration in older men and women that completed a randomized trial consisting of either a physical activity (PA) or successful aging health educational control (SA) group.

Isokinetic knee extensor strength and computed tomography-derived midthigh skeletal muscle and adipose tissue cross-sectional areas (CSA) were assessed at baseline and at 12 months following randomization. The results showed that total body weight and muscle CSA decreased in both groups, but these losses were not different between groups. However, strength adjusted for muscle mass decreased in SA, whereas the loss of strength was completely prevented in PA. In addition, there was a significant increase in muscle fat infiltration in SA, but this gain was nearly completely prevented in PA. These results suggested that regular physical activity prevents both the age-associated loss of muscle strength and increase in muscle fat infiltration in older adults with moderate functional limitations. ${ }^{31}$ In the present study these parameters were resembling between groups, also indicating that regular or irregular physical activity can affects similarly the elderly muscle and body fat composition and consequently muscular force parameters.

It is important to note that even though we found no significant differences in the variables studied between groups (IPA and RPA), except to TUG test, RPA subjects presented an average increase in most body composition parameters. In addition, the RPA group presented an average decrease in the muscle thickness and handgrip strength and an average increase in the sit and stand test.

These findings perhaps suggest that these elderly are more fragile than IPA and may have developed a subclinical process of sarcopenic obesity and so need regular physical activity as a way to secondary prevention. In the same way, we can think that the IPA group has a better health history, as well as more adequate nutritional habits (which may compensate for the irregular practice of physical activity) than the RPA group. However, to confirm this hypothesis, more studies evaluating nutritional habits and disease history in older people who exercise irregularly need to beconducted.

Finally, the results could be considered apparently contradictory, however it they may indicate that IPAQ instrument is not a good tool to evaluate the physical and fitness conditions of elderly people.

Additionally, it is important to ponder some considerations associated with our methodological design. Since the aging is strongly related to chronic degenerative morbidities, these diseases could affect the interpretation of the results. In fact, many investigations prefer to include a large number of subjects in the study and perform further exclusions when the statistical analyses are conducted. Of course, this approach increases the sample number and permits more consistent statistical power. However, with the great quantities of variables included in the study it becomes very difficult to discuss the results in biological terms.

For this reason, we chose to evaluate a reduced number of elderly subjects that present similarities of sex, age, and diseases and functional autonomy, which can interfere directly in the results obtained. When we carried 
out this selection, we had great difficulty to select RPA subjects. However, despite there are few numbers of subjects included in this study, these persons present a lower variability related to health profile that could impact results. Therefore, our results open the perspective to develop a complementary study to evaluate if regular and irregular physical activity also affects positively old subjects that present well established morbidities, highly prevalent in the elderly group.

\section{CONCLUSION}

The study showed no significant differences among elderly who performed physical activity in regular or irregular way in relation anthropometric and some body composition variables and force parameters. Additionally, it showed that elderly people who practice irregular physical activity have better performance in TUG test, suggesting that even irregular physical activity can help old individuals in mobility and prevention of falls.

Although the sample that performed physical activity on a regular basis is small compared with the irregularly active group, our results seem to highlight the importance of practicing physical activity, even if irregularly. It seems that physical activity being performed even irregularly can bring some benefit, mainly mobility for the elderly. However, further studies are needed with larger samples to confirm this hypothesis.

\section{REFERENCES}

1. Deschenes MR. Effects of aging on muscle fibre type and size. Sports Med 2004;34(12):809-24

2. Zech A,Steib S, Sportwiss D, Freiberger E, Pfeifer K. Functional Muscle Power Testing in Young, Middle-Aged, and Community-Dwelling Nonfrail and Prefrail Older Adults. Arch Phys Med Rehabil 2011;92(6):967-71.

3. Kim HK, Suzuki T, Saito K, Yoshida H, Kobayashi $\mathrm{H}$, Kato H, et al. Effects of Exercise and Amino Acid Supplementation on Body and Physical Function in Community-Dwelling Elderly Japanese Sarcopenic Women: A Randomized Controlled Trial. J Am Geriatr Soc 2012,60:16-23.

4. Sherrington C, Lord SR, Finch CF. Physical activity interventions to prevent falls among older people: update of the evidence. J Sci Med Sport 2004;7(1 Suppl):43-51.

5. Matsudo S, Araújo T, Marsudo V, Andrade D, Andrade E, Oliveria LC, et al. Questionário Internacional de Atividade Física (IPAQ): estudo de validade e reprodutibilidade no Brasil. Rev Bras Ativ Fis Saúde 2001;6(2)5-18.

6. International Physical Activity Questionnaire. Guidelines for Data Processing and Analysis of the International Physical Activity Questionnaire (IPAQ): short and Long Forms [Internet]. [S.1.]: IPAQ; 2002 [accessed May 2012]. Disponível em: http://www.ipaq.ki.se
7. Garrow JS, Webster J. Quetelet's index (W/H2) as a measure of fatness. Int J Obes 1985;9(2):147-53.

8. Lipschitz DA. Screening for nutritional status in the elderly. Prim Care 1994;21(1):55-67.

9. Alberti KG, Zimmet P, Shaw J. Metabolic syndrome: a new world-wide definition. A Consensus Statement from the International Diabetes Federation. Diabet Med 2006;23(5):469-80.

10. Center for Disease Control and Prevention, National Center for Health Statistics. National Health and Nutrition Examination Survey: Anthropometry Procedures Manual (NHANES) [Internet]. Atlanta, USA: CDC; 2007 [accessed Apr 2011]. Disponível em: http://www.cdc.gov/nchs/data/nhanes/ nhanes_07_08/manula_an.pdf

11. Lohman TG, Roche AF, Martorell R. Anthropometric standardization reference manual. Human Kinetics, Champaign; 1988.

12. Miyatani M, Kanehisa H, Ito M, Kawakami Y, Fukunaga $\mathrm{T}$. The accuracy of volume estimates using ultrasound muscle thickness measurements in different muscle groups. Eur J Appl Physiol 2004;91(2-3):264-72.

13. Fess EE. Grip strength. In: American Society of Hand Therapists, editor. Clinical Assessment Recommendations. Chicago: American Society of Hand Therapists; 1992. 41-5. 
14. Cruz-Jentoft AJ, Baeyens JP, Bauer JM, Boirie Y, Cederhom T, Landi F, et al. Sarcopenia: European consensus on definition and diagnosis. Report of the European Working Group on Sarcopenia in older People. Age Ageing 2010;39(4):412-23.

15. Bassey EJ, Fiatarone MA, O’Neill EF, Kelly M, Evans WJ, Lipsitz LA. Leg extensor power and functional performance in very old men and women. Clin Sci 1992;82(3):321-7.

16. Zech A, Steib S, Sportwiss D, Freiberger E, Pfeifer $K$. Functional muscle power testing in young, middle-aged, and community-dwelling nonfrail and prefrail older adults. Arch Phys Med Rehabil 2011;92(6):967-71.

17. Podsiadlo D, Richardson S. The Timed "Up \& Go": A test of basic functional mobility for frail elderly persons. J Am Geriatr Soc 1991;39(2):142-8.

18. Zorba E, Cengiz T, Karacabey K. Exercise training improves body composition, blood lipid profile and serum insulin levels in obese children. J Sports Med Phys Fitness 2011;51(4):664-9.

19. Villareal DT, Smith GI, Sinacore DR, Shah K, Mittendorfer B. Regular multicomponent exercise increases physical fitness and muscle protein anabolism in frail, obese, older adults. Obesity 2011;19(2):312-8.

20. Sanada K, Miyachi M, Tabata I, Suzuki K, Yamamoto $\mathrm{K}$, Kawano H, et al. Differences in body composition and risk of lifestyle-related diseases between young and older male rowers and sedentary controls.J Sports Sci 2009;27(10):1027-34.

21. Woods JL, Luliano-Burns S, King SJ, Strauss BJ, Walker KZ. Poor physical function in elderly women in low-level aged care is related to muscle strength rather than to measures of sarcopenia. Clin Interv Aging 2011;6:67-76.
22. Bize R, Johnson JA, Plotnikoff RC. Physical activity level and health-related quality of life in the general adult population: a systematic review. Prev Med 2007;45(6):401-15.

23. Park H, Park S, Shephard RJ, Aoyagi Y. Yearlong physical activity and sarcopenia in older adults: the Nakanojo Study. Eur J Appl Physiol 2010;109(5):953-61.

24. Warburton DER, Nicol CW, Bredin SSD. Health benefits of physical activity: the evidence. CMAJ 2006;174(6):801-9.

25. Wang CY, Yeh CJ, Wang CW, Wang CF, Lin YL. The health benefits following regular ongoing exercise lifestyle in independent community-dwelling older Taiwanese adults. Australas J Ageing 2011;30(1):22-6.

26. Wu SC, Leu SY, Li CY. Incidence of and predictors for chronic disability in activities of daily living among older people in Taiwan. J Am Geriatr Soc 1999;47(9):1082-6.

27. Beauchet O, Fantino B, Allali G, Muir SW, MonteroOdasso M, Annweiler C. Timed up and go test and risk of falls in older adults: a systematic review. J Nutr Health Aging 2011;15(10):933-8.

28. Krause MP, Hallage T, Gama MPR, Goss FL, Robertson R, Silva SG. Association of adiposity, cardiorespiratory fitness and exercise practice with the prevalence of type 2 diabetes in Brazilian elderly women. Int J Med Sci 2007;4(5):288-92.

29. Sofi F, Capalbo A, Marcucci R, Gori AM, Fedi S, Macchi C, et al. Leisure time but not occupational physical activity significantly affects cardiovascular risk factors in an adult population. Eur J Clin Invest 2007;37(12):947-53.

30. Goodpaster BH, Chomentowski P, Ward BK, Rossi A, Glynn NW, Delmonico MJ, et al. Effects of physical activity on strength and skeletal muscle fat infiltration in older adults: a randomized controlled trial. J Appl Physiol 2008;105(5):1498-503. 